УДК $519.63: 532.5$

\section{МАТЕМАТИЧНІ МОДЕЛІ ФІЛЬТРАЦІЙНИХ ТЕЧІЙ ТА ЗАСТОСУВАННЯ МЕТОДУ R-ФУНКЦІЙ ДЛЯ ÏХ ЧИСЕЛЬНОГО АНАЛІЗУ ПОДГОРНИЙ О.Р.}

Розглядаються постановки основних крайових задач для функції течії фільтраційного потоку. Для тестової крайової задачі теорії стаціонарної фільтрації у ізотропному грунті будується (відповідно до методу $R$ функцій) структура розв'язку крайової задачі та обгрунтовується застосування методу Рітца для апроксимації невизначеної компоненти структурної формули.

Ключові слова: закон Дарсі; фільтрація рідини у пористому середовищі; метод R-функцій; метод Рітца.

Key words: Darcy's law; fluid flow through porous media; boundary problem; R-function's method; Ritz method.

Вступ. Фільтрацією називається повільний рух (просочування) рідин, нафти та газу, газованої рідини у пористому середовищі під дією якихось факторів [16]. Явище фільтрації зустрічається у науці, промисловості, сільському господарстві тощо. Це процеси осушення і зрошення, втікання морської води в прісну, обтікання гідротехнічних споруд, просочування води крізь земляні дамби, задачі прийняття рішень і управління у надзвичайних ситуаціях, пов'язаних з паводками, та багато іншого.

При математичному моделюванні фільтраційних течій приходять до крайових задач для рівнянь у частинних похідних. Точні розв'язки таких задач можна у деяких випадках отримати, використовуючи методи теорії функцій комплексної змінної [11]. Більш універсальними є чисельні методи - метод сіток, метод скінченних елементів, метод мажорантних областей, метод суматорних подань, метод фіктивних областей тощо $[4,5,6$, $9,12,13]$. Кожен 3 цих методів має свої переваги та недоліки. До недоліків точних методів слід віднести обмежену кількість областей, до яких вони застосовні, а основним недоліком існуючих наближених методів $\epsilon$ те, що при їх реалізації у геометрично складних областях межа області апроксимується, наприклад, вписаною ламаною, тобто втрачається точність у врахуванні геометричної інформації у чисельному алгоритмі.

Найбільш точно і повно врахувати геометричну та аналітичну інформацію, яка міститься у постановці задачі математичної фізики, дозволяе структурний метод $R$-функцій [18]. Для численного розв'язання задач фільтрації метод $R$ функцій було застосовано у [2,3,19], але в них було розглянуто лише задачі фільтрації під гідротехнічними спорудами.

Отже, розробка нових та вдосконалення існуючих методів чисельного аналізу фільтраційних течій $\epsilon$ актуальною науковою задачею.

1. Мета та задачі дослідження. Метою роботи $\epsilon$ розробка нових та вдосконалення існуючих методів чисельного аналізу плоских стаціонарних фільтраційних течій на основі математичної моделі у термінах «функція течії». Для досягнення цієї мети необхідно:

- провести аналіз постановок можливих крайових задач для функції течії;

- для тестової задачі теорії фільтрації побудувати на основі методу R-функцій структуру розв'язку;

- обгрунтувати застосування варіаційних методів до апроксимації невизначених компонент побудованої структурної формули.

2. Математичні моделі теорії плоскої фільтрації. Побудова математичних моделей фільтраційних течій заснована на використанні закону, встановленого емпірично французьким інженером А. Дарсі (1803-1858) у 1852-1855 pp. [16]. Математичне формулювання закону Дарсі для ізотропного середовища має вигляд:

$$
\mathbf{v}=\kappa \mathbf{J}=-\kappa \frac{\mathrm{dH}}{\mathrm{d} \mathbf{s}},
$$

де $\mathbf{J}=-\frac{\mathrm{dH}}{\mathrm{ds}}-$ градієнт п’єзометричного напору

$$
\mathrm{H}=\frac{\mathrm{p}}{\rho \mathrm{g}}+\mathrm{z}(\rho \mathrm{g}=\gamma)
$$

за шляхом s; р - тиск; $\rho$ - щільність рідини; g - прискорення сили тяжіння; z - геометрична висота над деякою площиною порівняння; $\gamma$ питома вага рідини; к - коефіцієнт фільтрації. Закон Дарсі (1) означає, що втрати напору при фільтрації пропорційні іï швидкості.

Коефіцієнт фільтрації к залежить від властивостей як пористого середовища, так і рідини:

$$
\kappa=\frac{\mathrm{k} \rho \mathrm{g}}{\mu},
$$

де к - проникність пористого середовища; $\rho$ щільність рідини; g - прискорення сили тяжіння; $\mu$ - коефіцієнт динамічної в'язкості рідини. Типові значення к при фільтрації води у піску мають порядок $10^{-5} \div 10^{-2} \mathrm{M} / \mathrm{c}$, у грунті $10^{-6} \div 10^{-4} \mathrm{M} / \mathrm{c}$, у глині $-10^{-7} \div 10^{-6} \mathrm{M} / \mathrm{c}$.

При фільтрації у анізотропних пористих середовищах лінійна залежність швидкості фільтрації 
та градієнта тиску зберігається, але ці вектори у загальному випадку вже не будуть колінеарні. Коефіцієнт фільтрації наразі буде симетричним додатно-означеним тензором.

Критерієм застосовності закону Дарсі є малість числа Рейнольдса.

Якщо межа області фільтрації складається лише 3 проникних та непроникних ділянок, то фільтрацію називають напірною. Якщо ж до складу межі входять сухий чи змочений грунт, а також поверхні (проміжки) просочування, з яких рідина потрапляє безпосередньо в атмосферу, то фільтрацію називають безнапірною.

Основні рівняння гідромеханічної теорії фільтрації були отримані в роботах Н.Є. Жуковського [8] та М.М. Павловського [15].

Система рівнянь руху рідини у пористому середовищі має вигляд:

$$
\begin{gathered}
\frac{1}{\mathrm{~g}} \frac{\partial \mathrm{v}_{\mathrm{x}}}{\partial \mathrm{t}}+\frac{\partial \mathrm{H}}{\partial \mathrm{x}}+\frac{1}{\kappa} \mathrm{v}_{\mathrm{x}}=0, \\
\frac{1}{\mathrm{~g}} \frac{\partial \mathrm{v}_{\mathrm{y}}}{\partial \mathrm{t}}+\frac{\partial \mathrm{H}}{\partial \mathrm{y}}+\frac{1}{\kappa} \mathrm{v}_{\mathrm{y}}=0, \\
\frac{1}{\mathrm{~g}} \frac{\partial \mathrm{v}_{\mathrm{z}}}{\partial \mathrm{t}}+\frac{\partial \mathrm{H}}{\partial \mathrm{z}}+\frac{1}{\kappa} \mathrm{v}_{\mathrm{z}}=0, \\
\Pi \frac{\partial \mathrm{p}}{\partial \mathrm{t}}+\frac{\partial}{\partial \mathrm{x}}\left(\rho \mathrm{v}_{\mathrm{x}}\right)+\frac{\partial}{\partial \mathrm{y}}\left(\rho \mathrm{v}_{\mathrm{y}}\right)+\frac{\partial}{\partial \mathrm{z}}\left(\rho \mathrm{v}_{\mathrm{z}}\right)=0, \\
\mathrm{f}(\rho, \mathrm{H}, \mathrm{T})=0 .
\end{gathered}
$$

Рівняння (5) називається рівнянням нерозривності ( п - пористість грунту), а (6) - рівнянням стану, що характеризує стан рідини відношенням між густиною $\rho$, ізотермічним напором $\mathrm{H}$ та абсолютною температурою $\mathrm{T}$.

Система (2) - (6) є замкнутою системою рівнянь, які описують нестаціонарну фільтрацію важкої стисливої рідини у недеформованому грунті, якщо справедливий закон Дарсі.

Інтегруючи систему рівнянь (2) - (6) в області фільтрації (при крайових та початкових умовах), отримуємо проекції швидкості фільтрації, п’єзометричний напір та густину рідини, яка фільтрується.

Для нестисливих однорідних рідин рівняння стану має вигляд $\rho=$ const . Тоді рівняння нерозривності перетворюється на рівність:

$$
\frac{\partial \mathrm{v}_{\mathrm{x}}}{\partial \mathrm{x}}+\frac{\partial \mathrm{v}_{\mathrm{y}}}{\partial \mathrm{y}}+\frac{\partial \mathrm{v}_{\mathrm{z}}}{\partial \mathrm{z}}=0
$$

Для стаціонарної фільтрації з (2) - (4) отримаємо

$$
\mathrm{v}_{\mathrm{x}}=-\kappa \frac{\partial \mathrm{H}}{\partial \mathrm{x}}, \mathrm{v}_{\mathrm{y}}=-\kappa \frac{\partial \mathrm{H}}{\partial \mathrm{y}}, \mathrm{v}_{\mathrm{z}}=-\kappa \frac{\partial \mathrm{H}}{\partial \mathrm{z}} .
$$

Підстановкою (8) у (7) отримаємо, що напір Н задовольняє в області фільтрації однорідному еліптичному рівнянню

$$
-\frac{\partial}{\partial \mathrm{x}}\left(\kappa \frac{\partial \mathrm{H}}{\partial \mathrm{x}}\right)-\frac{\partial}{\partial \mathrm{y}}\left(\kappa \frac{\partial \mathrm{H}}{\partial \mathrm{y}}\right)-\frac{\partial}{\partial \mathrm{z}}\left(\kappa \frac{\partial \mathrm{H}}{\partial \mathrm{z}}\right)=0,
$$

яке для однорідно-ізотропного грунту ( $\kappa=$ const $)$ переходить у рівняння Лапласа

$$
\Delta \mathrm{H} \equiv \frac{\partial^{2} \mathrm{H}}{\partial \mathrm{x}^{2}}+\frac{\partial^{2} \mathrm{H}}{\partial \mathrm{y}^{2}}+\frac{\partial^{2} \mathrm{H}}{\partial \mathrm{z}^{2}}=0 .
$$

Ввівши потенціальну функцію $\varphi$ як

$$
\varphi=-\kappa \mathrm{H},
$$

3 (9) та (10) отримаємо, що при $\kappa=$ const функція $\varphi$ є гармонічною в області фільтрації:

$$
\Delta \varphi \equiv \frac{\partial^{2} \varphi}{\partial \mathrm{x}^{2}}+\frac{\partial^{2} \varphi}{\partial \mathrm{y}^{2}}+\frac{\partial^{2} \varphi}{\partial \mathrm{z}^{2}}=0 .
$$

Лінії рівня $\varphi=$ const функції $\varphi$ називаються еквіпотенціальними поверхнями (поверхнями рівного потенціалу), а враховуючи (11), вони є поверхнями рівного напору. Зрозуміло, що вектор швидкості фільтрації у будь-якій точці області фільтрації спрямований за нормаллю до поверхні рівного напору, який проходить через цю точку. У випадку плоскої стаціонарної фільтрації в однорідному ізотропному недеформованому грунті (фільтрація відбувається у площині, яка є паралельною до координатної площини хОу ) система (2) - (6) матиме вигляд:

$$
\mathrm{v}_{\mathrm{x}}=-\kappa \frac{\partial \mathrm{H}}{\partial \mathrm{x}}, \mathrm{v}_{\mathrm{y}}=-\kappa \frac{\partial \mathrm{H}}{\partial \mathrm{y}}, \frac{\partial \mathrm{v}_{\mathrm{x}}}{\partial \mathrm{x}}+\frac{\partial \mathrm{v}_{\mathrm{y}}}{\partial \mathrm{y}}=0,
$$

а рівняння (12) -

$$
\Delta \varphi \equiv \frac{\partial^{2} \varphi}{\partial \mathrm{x}^{2}}+\frac{\partial^{2} \varphi}{\partial \mathrm{y}^{2}}=0 .
$$

Плоскі фільтраційні течії зручно аналізувати за допомогою функції течії $\psi$, яка вводиться співвідношеннями:

$$
\mathrm{v}_{\mathrm{x}}=\frac{\partial \psi}{\partial \mathrm{y}}, \mathrm{v}_{\mathrm{x}}=-\frac{\partial \psi}{\partial \mathrm{x}} .
$$

Завдяки такому означенню функції течії $\psi$ рівняння нерозривності (третє з рівнянь (13)) обертається в тотожність, а з (8) матимемо, що

$$
\frac{\partial \mathrm{H}}{\partial \mathrm{x}}=-\frac{1}{\kappa} \frac{\partial \psi}{\partial \mathrm{y}}, \frac{\partial \mathrm{H}}{\partial \mathrm{y}}=\frac{1}{\kappa} \frac{\partial \psi}{\partial \mathrm{x}} .
$$

Оскільки $\varphi=-\kappa \mathrm{H}$, то за умови $\kappa=$ const функції $\varphi$ та $\psi$ пов'язані умовами Коші-Рімана:

$$
\frac{\partial \varphi}{\partial \mathrm{x}}=\frac{\partial \psi}{\partial \mathrm{y}}, \frac{\partial \varphi}{\partial \mathrm{y}}=-\frac{\partial \psi}{\partial \mathrm{x}} .
$$

Диференціюючи перше $з$ рівностей (16) за у i віднімаючи 3 нього друге 3 рівностей (16), яке 
продиференційоване за х, отримаємо, що функція течії задовольняє в області фільтрації рівняння

$$
-\frac{\partial}{\partial \mathrm{x}}\left(\frac{1}{\kappa} \frac{\partial \psi}{\partial \mathrm{x}}\right)-\frac{\partial}{\partial \mathrm{y}}\left(\frac{1}{\kappa} \frac{\partial \psi}{\partial \mathrm{y}}\right)=0 .
$$

Лінії рівня $\psi=$ const функції течії $\psi$ називають лініями течії. Вони мають властивість: вектор швидкості фільтрації в будь-якій точці області фільтрації спрямований за дотичною до лінії течії, що проходить через цю точку.

Рівняння для напору (9), (10), потенціалу (12), (14), функції течії (17), (18) необхідно доповнити крайовими умовами $[4,5,6]$.

На ділянках межі області фільтрації, які є непроникними поверхнями, нормальна складова швидкості повинна дорівнювати нулю (умова непротікання):

$$
\mathbf{v}_{\mathrm{n}}=0 .
$$

Прикладами таких ділянок $є$ поверхні бетонних основ гідроспоруд або межі піску та глини.

Із закону Дарсі та рівнянь (11), (17), (19) випливає, що на цих ділянках межі виконуються умови

$$
\frac{\partial \varphi}{\partial \mathbf{n}}=0, \psi=\text { const },
$$

тобто вони є лініями течії.

Деякі ділянки межі області фільтрації можуть межувати з областями вільної рідини. Прикладом такого випадку є межа між пористим середовищем та водоймою, через яку рідина просочується 3 водойми в грунт та навпаки - коли грунтові води можуть потрапляти у водойму. У цьому випадку на ділянках межі дотична складова швидкості повинна дорівнювати нулю:

$$
\mathbf{v}_{\mathbf{s}}=0 \text {. }
$$

Із закону Дарсі та рівнянь (11), (17), (19) випливає, що

$$
\varphi=\text { const }, \frac{\partial \psi}{\partial \mathbf{n}}=0,
$$

тобто вони є еквіпотенціальними лініями.

Припустимо, що область фільтрації частково межує 3 атмосферою. Такі межі називаються проміжками височування, оскільки на таких ділянках рідина може витікати 3 пористого середовища i, наприклад, стікати уздовж межі або випаровуватися. Прикладами таких меж служать стінки земляних гребель, через які фільтрується вода, або стінки колодязів, викопаних у водонасиченому грунті.

На проміжку височування мають місце умови неперервності тиску (якщо знехтувати капілярними ефектами, то тиск рідини в пористому се- редовищі на межі збігається 3 атмосферним) та додатності проекції швидкості фільтрації на зовнішню нормаль:

$$
\mathbf{v}_{\mathbf{n}}>0
$$

тобто рідина може тільки витікати 3 пористого середовища. Саме ж значення швидкості фільтрації на межі області розв'язання задачі є невідомим.

Частина межі області фільтрації може бути лінією розділу між сухим і вологим грунтом. Така ділянка називається вільною поверхнею (лінією) або поверхнею депресії. Відзначимо, що до розв'язання задачі іiі форма невідома. На ділянці вільної поверхні мають місце зазвичай загальна умова збереження маси і умова неперервності тиску. Крім того, ця крива $є$ лінією течії.

Тепер припустимо, що грунтова вода проходить крізь два грунти з різними коефіцієнтами фільтрації $\kappa_{1}$ и $\kappa_{2}$. Нехай грунти межують по деякій лінії L . На цій лінії повинні бути виконані умови неперервності тиску:

$$
\mathrm{p}_{1}=\mathrm{p}_{2} \text { в будь-якій точці } \mathrm{L}
$$

та нерозривності течії:

$$
\mathbf{v}_{1 \mathbf{n}}=\mathbf{v}_{2 \mathbf{n}} \text { в будь-якій точці L . }
$$

Тоді із закону Дарсі і рівнянь (11), (17) випливає, що на $L$ виконуються умови

$$
\begin{aligned}
& \frac{\varphi_{1}}{\kappa_{1}}=\frac{\varphi_{2}}{\kappa_{2}}, \frac{1}{\kappa_{1}} \frac{\partial \varphi_{1}}{\partial \mathrm{s}}=\frac{1}{\kappa_{2}} \frac{\partial \varphi_{2}}{\partial \mathrm{s}}, \\
& \psi_{1}=\psi_{2}, \frac{1}{\kappa_{1}} \frac{\partial \psi_{1}}{\partial \mathrm{n}}=\frac{1}{\kappa_{2}} \frac{\partial \psi_{2}}{\partial \mathrm{n}} .
\end{aligned}
$$

3. Конструктивний апарат теорії $R$-функцій та його застосування в математичному моделюванні фізико-механічних полів. Розглянемо основні відомості $з$ теорії $R$-функцій та загальну схему застосування методів цієї теорії у математичному моделюванні фізико-механічних полів $[10,18]$.

Вперше $R$-функції з'явилися у 1963 р. в роботі акад. НАН України В.Л. Рвачова [17]. Серед функцій неперервного аргументу ним було виділено клас функцій, які мають властивості, схожі 3 властивостями функцій дискретного аргументу, а саме - 3 функціями алгебри логіки.

Можна дати таке означення $[10,18]$.

Означення. Функція $\mathrm{y}=\mathrm{f}\left(\mathrm{x}_{1}, \ldots, \mathrm{x}_{\mathrm{n}}\right), \mathrm{f}: \mathbf{R}^{\mathrm{n}} \rightarrow \mathbf{R}$, називається R-функцією (функцією В.Л. Рвачова), що відповідає розбиттю множини $\mathbf{X}=(-\infty,+\infty)=\mathbf{R}$ на три градації:

$$
\mathrm{S}_{3}^{-1}(0)=\mathbf{X}(0)=(-\infty, 0), \mathrm{S}_{3}^{-1}(1)=\mathbf{X}(1)=\{0\},
$$




$$
\mathrm{S}_{3}^{-1}(2)=\mathbf{X}(2)=(0,+\infty),
$$

якщо існує така функція тризначної логіки $\mathrm{Y}=\mathrm{F}\left(\mathrm{X}_{1}, \ldots, \mathrm{X}_{\mathrm{n}}\right)$, що

$$
\mathrm{S}_{3}\left[\mathrm{f}\left(\mathrm{x}_{1}, \ldots, \mathrm{x}_{\mathrm{n}}\right)\right]=\mathrm{F}\left[\mathrm{S}_{3}\left(\mathrm{x}_{1}\right), \ldots, \mathrm{S}_{3}\left(\mathrm{x}_{\mathrm{n}}\right)\right],
$$

де $\mathrm{S}_{3}(\mathrm{t})= \begin{cases}0, & \mathrm{t}<0, \\ 1, & \mathrm{t}=0, \\ 2, & \mathrm{t}>0 .\end{cases}$

Множина всіх таких $R$-функцій позначається так: $\mathfrak{R}_{3}=\mathfrak{R}\left[\mathfrak{X}=(-\infty,+\infty) ; S_{3}\right]$.

Функція тризначної логіки $\mathrm{F}$, що задовольняе (21), називається супровідною для $R$-функції $\mathrm{f}$.

Множина $\mathfrak{R}_{3}$ має непустий перетин 3 множиною елементарних функцій, тому над $R$-функціями можна виконувати, зокрема, операції диференціювання та інтегрування.

На теперішній час відома велика кількість систем $R$-функцій [18]. Зокрема, система $\mathfrak{R}_{\alpha}$ має вигляд

$$
\begin{gathered}
\bar{x} \equiv-x ; \\
x_{1} \wedge_{\alpha} x_{2} \equiv \frac{1}{1+\alpha}\left(x_{1}+x_{2}-\sqrt{x_{1}^{2}+x_{2}^{2}-2 \alpha x_{1} x_{2}}\right) ; \\
x_{1} \vee_{\alpha} x_{2} \equiv \frac{1}{1+\alpha}\left(x_{1}+x_{2}+\sqrt{x_{1}^{2}+x_{2}^{2}-2 \alpha x_{1} x_{2}}\right) .
\end{gathered}
$$

Тут $\alpha\left(\mathrm{x}_{1}, \mathrm{x}_{2}\right)$ - довільна функція, яка задовольняє умови

$$
\begin{gathered}
-1<\alpha\left(\mathrm{x}_{1}, \mathrm{x}_{2}\right) \leq 1, \\
\alpha\left(\mathrm{x}_{1}, \mathrm{x}_{2}\right) \equiv \alpha\left(\mathrm{x}_{2}, \mathrm{x}_{1}\right) \equiv \alpha\left(-\mathrm{x}_{1}, \mathrm{x}_{2}\right) \equiv \alpha\left(\mathrm{x}_{1},-\mathrm{x}_{2}\right) \\
\text { для всіх } \mathrm{x}_{1}, \mathrm{x}_{2} \in \mathbf{R} .
\end{gathered}
$$

Для $R$-функцій (22) супровідними є функції тризначної логіки заперечення, диз'юнкція та кон'юнкція відповідно.

Розглянемо розв'язання методом $R$-функцій обернену задачу аналітичної геометрії. Ця задача полягає у наступному: нехай у $\mathbf{R}^{\mathrm{n}}$ задано геометричний об'єкт $\Omega$ з кусково-гладкою межею $\partial \Omega$ i необхідно побудувати таку функцію $\omega(\mathbf{x})$, яка додатна всередині $\Omega$ і дорівнює нулю на $\partial \Omega$. Тоді рівняння $\omega(\mathbf{x})=0$ у неявній формі визначатиме геометричне місце точок, що є межею геометричного об'єкта $\Omega$.

Нехай геометричний об'єкт $\Omega$ побудовано з опірних множин $\Sigma_{\mathrm{i}}=\left(\sigma_{\mathrm{i}}(\mathbf{x}) \geq 0\right), \mathrm{i}=1, \ldots, \mathrm{m}$, за допомогою операцій $-, \wedge, \vee$ алгебри логіки над ними:

$$
\Omega=\mathrm{F}\left(\Sigma_{1}, \ldots, \Sigma_{\mathrm{m}}\right) .
$$

Вважаємо, що $\sigma_{i}(\mathbf{x}), i=1, \ldots, m,-$ прості непере- рвні (елементарні) функції, тобто $\sigma_{\mathrm{i}}(\mathbf{x})=0$ є межею множин $\sigma_{\mathrm{i}}(\mathbf{x}) \geq 0$ i $\sigma_{\mathrm{i}}(\mathbf{x})>0$.

Якщо тепер у (23) провести формальну заміну $\Omega$ на $\omega(\mathbf{x}), \Sigma_{\mathrm{i}}$ на $\sigma_{\mathrm{i}}(\mathbf{x}), \mathrm{i}=1, \ldots, \mathrm{m}$, а символів,$- \wedge$, $\checkmark$ алгебри логіки на символи відповідних $R$ операцій, то отримаємо аналітичний вираз, який в елементарних функціях визначає рівняння межi $\partial \Omega[9]$ :

$$
\omega(\mathbf{x})=0 .
$$

При цьому для внутрішніх точок $\Omega$ виконується нерівність $\omega(\mathbf{x})>0$.

На функцію $\omega(\mathbf{x})$ також можна накладати додаткові умови: наприклад, умову нормалізованості, яка полягає у задоволенні вимог

$$
\begin{aligned}
\omega(\mathbf{x})=0 \text { на } \partial \Omega ; \omega(\mathbf{x})>0 \text { всередині } \Omega ; \\
\left.\frac{\partial \omega}{\partial \mathbf{n}}\right|_{\partial \Omega}=-1,
\end{aligned}
$$

де $\mathbf{n}$ - зовнішня до $\partial \Omega$ нормаль.

При розв'язанні диференціальних задач математичної фізики метод $R$-функцій дозволяє побудувати так звану структуру розв'язку крайової задачі, тобто жмуток функцій, який точно задовольняє всім крайовим умовам задачі та залежить від деяких невизначених компонент. Вибір цих невизначених компонент роблять так, щоб у деякому сенсі задовольнити диференціальне рівняння задачі. Для цього використовуються різні чисельні методи математичної фізики, зокрема, метод Рітца, метод найменших квадратів, метод Гальоркіна тощо.

Перевагою цього підходу порівняно, наприклад, 3 різницевими методами і методом скінченних елементів $\epsilon$ те, що геометрія розрахункової області враховується точно, тобто, зокрема, не відбувається заміни криволінійних ділянок.

Схему застосування методу $R$-функцій в задачах чисельного аналізу фізико-механічних полів можна розбити на такі етапи:

1) точний аналітичний опис геометрії розрахункової області, тобто побудова функції $\omega(\mathbf{x}) 3$ властивостями (24);

2) продовження крайових умов всередину області, тобто довизначення функцій та операторів, заданих на межі, у внутрішніх точках області;

3) побудова загальної структури розв'язку, тобто такої формули, яка залежить від деяких невизначених функцій (компонент) та за будь-якого їх вибору точно задовольняе всім крайовим умовам задачі;

4) побудова наближеного розв'язку, тобто апрок- 
симація невизначених компонент структури деяким чисельним методом.

Для продовження крайових умов всередину області використовуються два основних підходи [18].

Нехай функція $\varphi_{0}$ в точках $\partial \Omega$ задана у вигляді

$$
\varphi_{0}(s)=\left\{\begin{array}{cc}
\varphi_{0}^{(1)}(s), & s \in \partial \Omega_{1}, \\
\mathrm{~K} & \mathrm{~K} \\
\varphi_{0}^{(r)}(s), & s \in \partial \Omega_{r},
\end{array}\right.
$$

де ділянки межі $\partial \Omega_{1}, \ldots, \partial \Omega_{r}$ попарно різні, не мають спільних внутрішніх точок i $\partial \Omega=\partial \Omega_{1} \cup \mathrm{K} \partial \Omega_{r}$.

Нехай далі $\varphi_{i}(\mathbf{x}), i=1, \ldots, r$, такі, що $\left.\varphi_{i}\right|_{\partial \Omega_{i}}=\varphi_{0}^{(i)}, \mathrm{a}$ $\omega_{i}(\mathbf{x}), \quad i=1, \ldots, r$, такі, що $\omega_{i}(\mathbf{x})=0 \quad$ на $\partial \Omega_{i} \quad$ i $\omega_{i}(\mathbf{x})>0$ в $\bar{\Omega} \backslash \partial \Omega_{i}$. Тоді функція

$$
\varphi=\frac{\frac{\varphi_{1}}{\omega_{1}}+\ldots+\frac{\varphi_{r}}{\omega_{r}}}{\frac{1}{\omega_{1}}+\ldots+\frac{1}{\omega_{r}}}=\frac{\sum_{i=1}^{r} \varphi_{i} \prod_{\substack{j=1 \\ j \neq i}}^{r} \omega_{j}}{\sum_{i=1}^{r} \prod_{\substack{j=1 \\ j \neq i}}^{r} \omega_{j}}
$$

має властивість $\left.\varphi\right|_{\partial \Omega}=\varphi_{0}$.

Формулу (25) називають формулою «склейки» $\mathrm{i}$ позначають $\varphi=\mathrm{EC} \varphi_{0}$, де ЕС - оператор склеювання межових значень.

Другий підхід пов'язаний з продовженням диференціальних операторів, які задані на $\partial \Omega$, в середину області $\Omega$. Нехай $\omega=0$ - нормалізоване рівняння межі $\partial \Omega$ області $\Omega$. Тоді оператор $D_{1}$, який діє за правилом

$$
D_{1} u \equiv(\nabla \omega, \nabla u)=\sum_{i=1}^{n} \frac{\partial \omega}{\partial x_{i}} \frac{\partial u}{\partial x_{i}},
$$

в регулярних точках $\partial \Omega$ задовольняє рівність

$$
-\left.D_{1} u\right|_{\partial \Omega}=\frac{\partial u}{\partial \mathbf{n}}
$$

де $\mathbf{n}-$ зовнішня до $\partial \Omega$ нормаль.

При цьому вираз $D_{1} u$ має сенс всюди в $\Omega \cup \partial \Omega$. За допомогою оператора $D_{1}$ будують жмутки функцій, нормальна похідна яких, або лінійна комбінація нормальної похідної і самої функції на межі області приймає задані значення.

Деякими класичними прикладами структур розв'язку є:

- структура розв'язку, яка точно враховує крайову умову Діріхле $\left.\mathrm{u}\right|_{\partial \Omega}=\varphi_{0}(\mathrm{~s}), \mathrm{s} \in \partial \Omega$ :

$$
\mathrm{u}=\varphi+\omega \Phi ;
$$

- структура розв’язку, яка точно враховує крайо- ву умову Неймана $\left.\frac{\partial \mathrm{u}}{\partial \mathbf{n}}\right|_{\partial \Omega}=\varphi_{0}(\mathrm{~s}), \mathrm{s} \in \partial \Omega$ :

$$
\mathrm{u}=-\omega \varphi+\Phi-\omega \mathrm{D}_{1} \Phi \text {. }
$$

У формулах (26), (27) $\varphi=\mathrm{EC} \varphi_{0}, \omega(\mathbf{x})$ задовольняє умови (24), Ф - невизначена компонента.

Загальний метод побудови структурних формул розглянуто у $[10,18]$. Основні застосування методу $R$-функцій до розрахунку різних фізикомеханічних полів містяться у [7, 10, 14, 18, 20 та iн.].

4. Побудова структури розв'язку тестової задачі теорії фільтрації. Розглянемо таку крайову задачу теорії стаціонарної фільтрації:

$$
\begin{gathered}
-\frac{\partial}{\partial \mathrm{x}}\left(\frac{1}{\kappa} \frac{\partial \psi}{\partial \mathrm{x}}\right)-\frac{\partial}{\partial \mathrm{y}}\left(\frac{1}{\kappa} \frac{\partial \psi}{\partial \mathrm{y}}\right)=0 \mathrm{y} \Omega, \\
\left.\psi\right|_{\partial \Omega_{1}}=0,\left.\psi\right|_{\partial \Omega_{3}}=\mathrm{Q}, \\
\left.\frac{\partial \psi}{\partial \mathbf{n}}\right|_{\partial \Omega_{2}}=0,\left.\frac{\partial \psi}{\partial \mathbf{n}}\right|_{\partial \Omega_{4}}=0 .
\end{gathered}
$$

Розрахункова область $\Omega$ (область фільтраціі) наведена на рисунку.

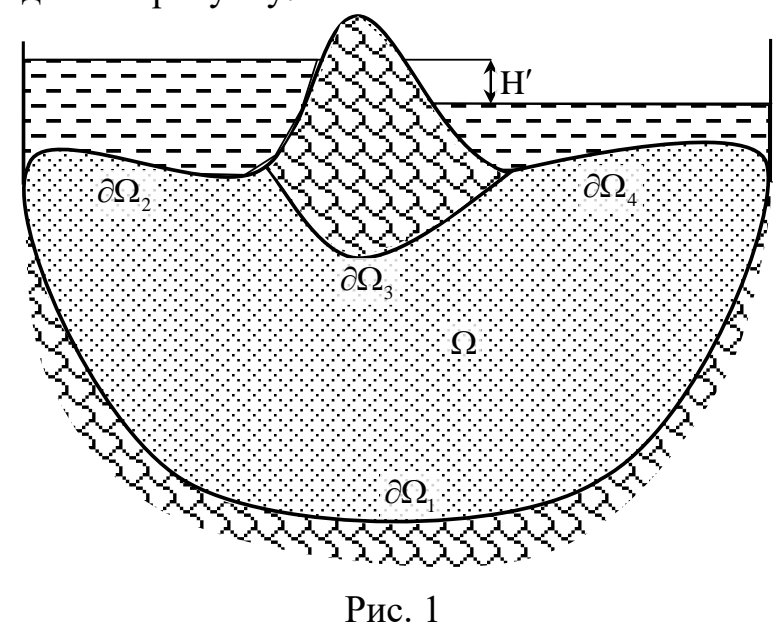

Межа $\partial \Omega$ області $\Omega$ складається 3 чотирьох ділянок: $\partial \Omega=\partial \Omega_{1} \cup \partial \Omega_{2} \cup \partial \Omega_{3} \cup \partial \Omega_{4}$. На ділянках $\partial \Omega_{2}, \partial \Omega_{4}$ грунт межує з областями вільної рідини (наприклад, це дно водойми), а ділянки $\partial \Omega_{1}$, $\partial \Omega_{3}$ відповідають непроникним поверхням (гранітна основа або бетонна гідротехнічна споруда). Задачу (28) - (30) можна розглядати як тестову

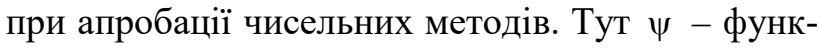
ція течії, к - коефіцієнт фільтрації , n - зовнішня нормаль до відповідних ділянок межі, Q повна витрата рідини, $\mathrm{H}^{\prime}$ - діючий напір.

Стала величина Q $є$ невідомою і визначається інтегральним співвідношенням

$$
\int_{\partial \Omega_{3}} \frac{1}{\kappa} \frac{\partial \psi}{\partial \mathbf{n}} \mathrm{ds}=-\mathrm{H}^{\prime} .
$$


Помітимо, що якщо и - розв'язок задачі

$$
\begin{gathered}
-\frac{\partial}{\partial \mathrm{x}}\left(\frac{1}{\kappa} \frac{\partial \mathrm{u}}{\partial \mathrm{x}}\right)-\frac{\partial}{\partial \mathrm{y}}\left(\frac{1}{\kappa} \frac{\partial \mathrm{u}}{\partial \mathrm{y}}\right)=0 \mathrm{y} \Omega, \\
\left.\mathrm{u}\right|_{\partial \Omega_{1}}=0,\left.\mathrm{u}\right|_{\partial \Omega_{3}}=1, \\
\left.\frac{\partial \mathrm{u}}{\partial \mathbf{n}}\right|_{\partial \Omega_{2}}=0,\left.\frac{\partial \mathrm{u}}{\partial \mathbf{n}}\right|_{\partial \Omega_{4}}=0,
\end{gathered}
$$

то функція $\psi=\mathrm{Qu}$, де відповідно до (31)

$$
\mathrm{Q}=-\mathrm{H}^{\prime} \cdot\left(\int_{\partial \Omega_{3}} \frac{1}{\kappa} \cdot \frac{\partial \mathrm{u}}{\partial \mathbf{n}} \mathrm{ds}\right)^{-1},
$$

є розв'язком задачі (28) - (30).

Відповідно до структурного методу R-функцій побудуємо структуру розв'язку крайової задачі (32) - (34). Нехай відомі функції $\omega(x, y), \omega_{\mathrm{i}}(\mathrm{x}, \mathrm{y})$, $\mathrm{i}=1,2,3,4$, такі що:

$$
\begin{gathered}
\omega(\mathrm{x}, \mathrm{y})=0 \text { на } \partial \Omega ; \omega(\mathrm{x}, \mathrm{y})>0 \text { у } \Omega ;\left.\frac{\partial \omega}{\partial \mathbf{n}}\right|_{\partial \Omega}=-1, \\
\omega_{\mathrm{i}}(\mathrm{x}, \mathrm{y})=0 \text { на } \partial \Omega_{\mathrm{i}} ; \quad \omega(\mathrm{x}, \mathrm{y})>0 \text { у } \Omega \cup\left(\partial \Omega \backslash \partial \Omega_{\mathrm{i}}\right) ; \\
\left.\frac{\partial \omega_{\mathrm{i}}}{\partial \mathbf{n}}\right|_{\partial \Omega_{\mathrm{i}}}=-1, \mathrm{i}=1,2,3,4 .
\end{gathered}
$$

Якщо межа $\partial \Omega$ складається зі скінченної кількості кусково-гладких кривих, кожна 3 яких може бути описана елементарною функцією, то функції зі вказаними властивостями можна побудувати у вигляді єдиного аналітичного виразу, користуючись конструктивним апаратом теорії $R$ функцій [18], причому вони також будуть функціями елементарними із заданими диференціальними властивостями.

За допомогою формули «склейки» (25) будуємо функцію

$$
f(x, y)=\frac{\omega_{3}(x, y)}{\omega_{1}(x, y)+\omega_{3}(x, y)},
$$

яка має властивість

$$
\left.\mathrm{f}\right|_{\partial \Omega_{1}}=0,\left.\mathrm{f}\right|_{\partial \Omega_{3}}=1 .
$$

Тоді крайові умови (33) можна записати у вигляді

$$
\left.(\mathrm{u}-\mathrm{f})\right|_{\partial \Omega_{1} \cup \partial \Omega_{3}}=0 .
$$

А за допомогою диференціального оператора

$$
\mathrm{D}_{1}^{(2-4)} \mathrm{u}=\left(\nabla \omega_{2-4}, \nabla \mathrm{u}\right)=\frac{\partial \omega_{2-4}}{\partial \mathrm{x}} \frac{\partial \mathrm{u}}{\partial \mathrm{x}}+\frac{\partial \omega_{2-4}}{\partial \mathrm{y}} \frac{\partial \mathrm{u}}{\partial \mathrm{y}},
$$

де $\omega_{2-4}(x, y)=\omega_{2}(x, y) \wedge_{\alpha} \omega_{4}(x, y)$, крайові умови

(34) запишуться так:

$$
\left.\mathrm{D}_{1}^{(2-4)} \mathrm{u}\right|_{\partial \Omega_{2} \cup \partial \Omega_{4}}=0 .
$$

3 (35) випливає, що функція и належить жмутку функцій вигляду

$$
\mathrm{u}=\mathrm{f}+\omega_{1-3} \Phi,
$$

де $\omega_{1-3}(\mathrm{x}, \mathrm{y})=\omega_{1}(\mathrm{x}, \mathrm{y}) \wedge_{\alpha} \omega_{3}(\mathrm{x}, \mathrm{y}), \Phi=\Phi(\mathrm{x}, \mathrm{y})-$ невизначена компонента.

3 умови (36) витікає, що

$$
\mathrm{D}_{1}^{(2-4)} \mathrm{u}=\omega_{2-4} \Psi .
$$

Подамо невизначену компоненту $\Phi$ у вигляді

$$
\Phi=\Phi_{1}+\omega_{2-4} \Phi_{2}
$$

і підберемо $\Phi_{1}, \Phi_{2}$ такими, щоб виконувалась умова (37). Матимемо:

$$
\begin{gathered}
\mathrm{D}_{1}^{(2-4)} \mathrm{u}=\mathrm{D}_{1}^{(2-4)}\left(\mathrm{f}+\omega_{1-3} \Phi\right)= \\
=\mathrm{D}_{1}^{(2-4)}\left(\mathrm{f}+\omega_{1-3} \Phi_{1}+\omega_{1-3} \omega_{2-4} \Phi_{2}\right)= \\
=\mathrm{D}_{1}^{(2-4)} \mathrm{f}+\mathrm{D}_{1}^{(2-4)}\left(\omega_{1-3} \Phi_{1}\right)+ \\
+\omega_{2-4} \mathrm{D}_{1}^{(2-4)}\left(\omega_{1-3} \Phi_{2}\right)+\omega_{1-3} \Phi_{2} \mathrm{D}_{1}^{(2-4)} \omega_{2-4}= \\
=\mathrm{D}_{1}^{(2-4)} \mathrm{f}+\mathrm{D}_{1}^{(2-4)}\left(\omega_{1-3} \Phi_{1}\right)+ \\
+\omega_{2-4} \mathrm{D}_{1}^{(2-4)}\left(\omega_{1-3} \Phi_{2}\right)+\omega_{1-3} \Phi_{2}\left(1+\omega_{2-4} \chi\right) .
\end{gathered}
$$

Тоді рівність (37) набуде вигляду

$$
\begin{gathered}
\mathrm{D}_{1}^{(2-4)} \mathrm{f}+\mathrm{D}_{1}^{(2-4)}\left(\omega_{1-3} \Phi_{1}\right)+ \\
+\omega_{2-4} \mathrm{D}_{1}^{(2-4)}\left(\omega_{1-3} \Phi_{2}\right)+\omega_{1-3} \Phi_{2}\left(1+\omega_{2-4} \chi\right)=\omega_{2-4} \Psi .
\end{gathered}
$$

Додавши до обох частин останньої рівності доданок $\omega_{2-4} \Phi_{2}$, отримаємо

$\mathrm{D}_{1}^{(2-4)} \mathrm{f}+\mathrm{D}_{1}^{(2-4)}\left(\omega_{1-3} \Phi_{1}\right)+\left(\omega_{1-3}+\omega_{2-4}\right) \Phi_{2}=\omega_{2-4} \Psi_{0}$, де $\Psi_{0}=\Phi_{2}+\Psi-\mathrm{D}_{1}^{(2-4)}\left(\omega_{1-3} \Phi_{2}\right)-\omega_{1-3} \Phi_{2} \chi$.

Звідси

$$
\begin{gathered}
\Phi_{2}= \\
=\frac{1}{\omega_{1-3}+\omega_{2-4}}\left[-\mathrm{D}_{1}^{(2-4)} \mathrm{f}-\mathrm{D}_{1}^{(2-4)}\left(\omega_{1-3} \Phi_{1}\right)+\omega_{2-4} \Psi_{0}\right]
\end{gathered}
$$

i

$$
\begin{gathered}
\mathrm{u}=\mathrm{f}+\omega_{1-3} \Phi_{1}+\omega_{1-3} \omega_{2-4} \Phi_{2}= \\
=\mathrm{f}+\omega_{1-3} \Phi_{1}+ \\
+\frac{\omega_{1-3} \omega_{2-4}}{\omega_{1-3}+\omega_{2-4}}\left[-\mathrm{D}_{1}^{(2-4)} \mathrm{f}-\mathrm{D}_{1}^{(2-4)}\left(\omega_{1-3} \Phi_{1}\right)+\omega_{2-4} \Psi_{0}\right] .
\end{gathered}
$$

Покладемо $\Psi_{0}=0$. Тоді структуру розв'язку задачі (32) - (34) отримаємо у вигляді (перепозначимо $\Phi_{1}$ на $\left.\Phi\right)$

$$
\begin{gathered}
\mathrm{u}=\mathrm{f}-\frac{\omega_{1-3} \omega_{2-4}}{\omega_{1-3}+\omega_{2-4}} \mathrm{D}_{1}^{(2-4)} \mathrm{f}+ \\
+\omega_{1-3} \Phi-\frac{\omega_{1-3} \omega_{2-4}}{\omega_{1-3}+\omega_{2-4}} \mathrm{D}_{1}^{(2-4)}\left(\omega_{1-3} \Phi\right) .
\end{gathered}
$$

Теорема 1. Структура розв'язку крайової задачі (32) - (34), яка точно задовольняе крайові умови (33), (34), має вигляд (38).

5. Метод знаходження чисельного розв'язку тестової задачі теорії фільтрації. Формула (38) при будь-якому виборі невизначеної компоненти 
Ф точно задовольняє крайові умови (33), (34). Для знаходження наближеного розв'язку (32) (34) апроксимуємо Ф 3 використанням методу Рітца.

У задачі (32) - (34) зробимо заміну

$$
\mathrm{u}=\mathrm{g}+\mathrm{v} \text {, }
$$

де $\mathrm{g}=\mathrm{f}-\frac{\omega_{1-3} \omega_{2-4}}{\omega_{1-3}+\omega_{2-4}} \mathrm{D}_{1}^{(2-4)} \mathrm{f}, \mathrm{v}-$ нова невідома

функція. Тоді для v отримаємо задачу з однорідними крайовими умовами:

$$
\begin{gathered}
-\frac{\partial}{\partial \mathrm{x}}\left(\frac{1}{\kappa} \frac{\partial \mathrm{v}}{\partial \mathrm{x}}\right)-\frac{\partial}{\partial \mathrm{y}}\left(\frac{1}{\kappa} \frac{\partial \mathrm{v}}{\partial \mathrm{y}}\right)=\mathrm{F} \mathrm{y} \Omega, \\
\left.\mathrm{v}\right|_{\partial \Omega_{1} \cup \partial \Omega_{3}}=0,\left.\frac{\partial \mathrm{v}}{\partial \mathbf{n}}\right|_{\partial \Omega_{2} \cup \partial \Omega_{4}}=0,
\end{gathered}
$$$$
\text { де } \mathrm{F}=\frac{\partial}{\partial \mathrm{x}}\left(\frac{1}{\kappa} \frac{\partial \mathrm{g}}{\partial \mathrm{x}}\right)+\frac{\partial}{\partial \mathrm{y}}\left(\frac{1}{\kappa} \frac{\partial \mathrm{g}}{\partial \mathrm{y}}\right) \text {. }
$$

Введемо у розгляд оператор А крайової задачі (39), (40), який діє за правилом

$$
\mathrm{Av}=-\frac{\partial}{\partial \mathrm{x}}\left(\frac{1}{\kappa} \frac{\partial \mathrm{v}}{\partial \mathrm{x}}\right)-\frac{\partial}{\partial \mathrm{y}}\left(\frac{1}{\kappa} \frac{\partial \mathrm{v}}{\partial \mathrm{y}}\right)
$$

на області визначення $\mathrm{D}_{\mathrm{A}}$, що складається 3 тих функцій простору $\mathrm{L}_{2}(\Omega)$, які належать множині $\mathrm{C}^{2}(\Omega) \cap \mathrm{C}^{1}(\bar{\Omega})$ та задовольняють крайові умови (40).

Можна показати, що цей оператор буде додатноозначеним, а отже, задача (39), (40) еквівалентна задачі знаходження у відповідному енергетичному просторі $\mathrm{H}_{\mathrm{A}}$ мінімуму функціонала енергії

$$
J[v]=[v, v]-2(F, v) \text {, }
$$

де

$$
\begin{gathered}
{[\mathrm{v}, \mathrm{v}]=\int_{\Omega} \frac{1}{\kappa}\left[\left(\frac{\partial \mathrm{v}}{\partial \mathrm{x}}\right)^{2}+\left(\frac{\partial \mathrm{v}}{\partial \mathrm{y}}\right)^{2}\right] \mathrm{dxdy},} \\
(\mathrm{F}, \mathrm{v})=\int_{\Omega} \mathrm{F} \cdot \mathrm{v} \mathrm{dxdy} .
\end{gathered}
$$

Наближений розв'язок цієї екстремальної задачі відповідно до методу Рітца шукатимемо у вигляді

$$
\mathrm{v}_{\mathrm{n}}=\sum_{\mathrm{k}=1}^{\mathrm{n}} \mathrm{c}_{\mathrm{k}} \varphi_{\mathrm{k}} .
$$

Елементи координатної послідовності $\left\{\varphi_{\mathrm{k}}\right\}$ відповідно до структури (38) обираємо у вигляді

$$
\varphi_{\mathrm{k}}=\omega_{1-3} \tau_{\mathrm{k}}-\frac{\omega_{1-3} \omega_{2-4}}{\omega_{1-3}+\omega_{2-4}} \mathrm{D}_{1}^{(2-4)}\left(\omega_{1-3} \tau_{\mathrm{k}}\right),
$$

де $\left\{\tau_{\mathrm{k}}\right\}$ - будь-яка повна у $\mathrm{L}_{2}(\Omega)$ система функцій (поліноми, сплайни тощо).

Тоді для визначення сталих $\mathrm{c}_{\mathrm{k}}, \mathrm{k}=1,2, \ldots, \mathrm{n}$, маємо систему лінійних алгебраїчних рівнянь

$$
\sum_{\mathrm{k}=1}^{\mathrm{n}}\left[\varphi_{\mathrm{k}}, \varphi_{\mathrm{j}}\right] \mathrm{c}_{\mathrm{k}}=\left(F, \varphi_{\mathrm{j}}\right), \mathrm{j}=1,2, \ldots, \mathrm{n},
$$

де

$$
\begin{aligned}
{\left[\varphi_{\mathrm{k}}, \varphi_{\mathrm{j}}\right] } & =\int_{\Omega} \frac{1}{\kappa}\left[\frac{\partial \varphi_{\mathrm{k}}}{\partial \mathrm{x}} \frac{\partial \varphi_{\mathrm{j}}}{\partial \mathrm{x}}+\frac{\partial \varphi_{\mathrm{k}}}{\partial \mathrm{y}} \frac{\partial \varphi_{\mathrm{j}}}{\partial \mathrm{y}}\right] \mathrm{dxdy}, \\
\left(\mathrm{F}, \varphi_{\mathrm{j}}\right) & =\int_{\Omega} \mathrm{F} \cdot \varphi_{\mathrm{j}} \mathrm{dxdy}, \mathrm{k}, \mathrm{j}=1,2, \ldots, \mathrm{n} .
\end{aligned}
$$

Iз загальних теорем збіжності методу Рітца та викладеного вище випливає така теорема.

Теорема 2. Нехай $\mathrm{F} \in \mathrm{L}_{2}(\Omega)$. Тоді послідовність

$$
\psi_{\mathrm{n}}=\mathrm{Q}_{\mathrm{n}} \mathrm{u}_{\mathrm{n}} \text {, }
$$

$\partial e$

$$
\mathrm{Q}_{\mathrm{n}}=-\mathrm{H}^{\prime} \cdot\left(\int_{\partial \Omega_{3}} \frac{1}{\kappa} \cdot \frac{\partial \mathrm{u}_{\mathrm{n}}}{\partial \mathbf{n}} \mathrm{ds}\right)^{-1}, \mathrm{u}_{\mathrm{n}}=\mathrm{f}+\mathrm{v}_{\mathrm{n}},
$$

збігається у $\mathrm{L}_{2}(\Omega)$ до узагальненого розв'язку задачі (28) - (30).

6. Висновки. Розглянуто основні математичні моделі фільтраційних течій, зокрема, постановка найпростішої задачі фільтрації, яка може слугувати тестовим прикладом для перевірки роботи чисельних методів. Для цієї крайової задачі отримано структуру розв'язку та обгрунтовано застосування метода Рітца для апроксимації невизначеної компоненти.

Отже, отримано подальший розвиток застосування структурного методу R-функцій у математичному моделюванні фізико-механічних полів, а також вдосконалено метод математичного моделювання фільтраційних течій у частині урахування у чисельному методі додаткового інтегрального співвідношення для знаходження повних витрат рідини.

Отримані результати можуть бути поширені на інші крайові задачі теорії фільтрації, а також можуть застосовуватись у розв'язанні прикладних задач, пов'язаних з розрахунком фільтраційних течій. Це i визначає наукову новизну та практичну значущість отриманих у роботі результатів.

Література: 1. Блишун А.П., Сидоров М.В. Метод численного анализа стационарного фильтрационного течения под гидротехническим сооружением в кусочнооднородному грунте // Вісник Запорізького національного університету. Серія: фізико-математичні науки. 2012. № 2. С. 5-12. 2. Блишун А.П., Сидоров М.В., Яловега И.Г. Математическое моделирование и численный анализ фильтрационных течений под гидротехническими сооружениями с помощью метода R-функций // Радиоэлектроника и информатика. 2010. № 2. С. 40-46. 3. Блишун А.П., Сидоров М.В., Яловега И.Г. Применение метода R-функций к численному анализу фильтрационных течений под гидротехническими сооружениями // Вісник Запорізького національного університету. 
Серія: фізико-математичні науки. 2012. № 1. С. 50-56. 4. Бомба А.Я., Булавацький В.М., Скопецький В.В. Нелінійні математичні моделі процесів геогідродинаміки. К.: Наук. думка, 2007. 292 с. 5. Вабищевич П.Н. Метод фиктивных областей в математической физике. М.: Изд-во МГУ, 1991. 156 с. 6. Венгерський П. Про задачу сумісного руху поверхневих і грунтових потоків на території водозбору //Вісник Львів. ун-ту. Сер. прикл. матем. та інф. Вип. 22, 2014. С. 41-53. 7. Гибкина Н.В., Роговой Н.С., Сидоров М.В., Стадникова А.В. Численный анализ задачи перемешивания вязкой жидкости, вызванного системой точечных вихрей // Вісник Запорізького національного університету. Серія: фізикоматематичні науки. 2013. № 2. С. 11-21. 8. Жуковский H.E. Теоретическое исследование о движении почвенных вод (1889). Полное собр. соч., т. 7. М.: 1937. С. 933. 9. Коннор Дж., Бреббиа К. Метод конечных элементов в механике жидкости. Л.: Судостроение, 1979. 264 c. 10. Кравченко В.Ф., Рвачев В.Л. Алгебра логики, атомарные функции и вейвлеты в физических приложениях. М.: Физматлит, 2006. 416 с. 11. Лаврентьев М.A., Шабат Б.В. Методы теории функций комплексного переменного. М.: Наука, 1973. 736 с. 12. Ляшко И.И., Великоиваненко И.М., Лаврик В.И., Мистецьький Г.E. Метод мажорантных областей в теории фильтрации. К. : Наук. думка, 1974. 202 с. 13. Ляшко Н.И., Великоиваненко Н.М. Численно-аналитическое решение краевых задач теории фильтрации. К. : Наук. думка, 1973. 264 с. 14. Максименко-Шейко К.В. R-функции в математическом моделировании геометрических объектов и физических полей. Харків. ІПМаш НАН України, 2009. 306 с. 15. Павловский Н.Н. Теория движения грунтовых вод под. гидротехническими сооружениями и её основные приложения. Петроград, Издво Научн.-мелиорац. ин-та, 1922. 752 с. 16. Полубаринова-Кочина П.Я. Теория движения грунтовых вод. М.: Наука, 1977. 664 с. 17. Рвачев В.Л. Об аналитическом описании некоторых геометрических объектов. Докл. АН СССР. 1963. 153, № 4. С. 765-768. 18. Рвачев В.Л. Теория R-функций и некоторые её приложения. К.: Наук. думка, 1982. 552 с. 19. Сидоров М.B., Стороженко A.B. Математическое компьютерное моделирование некоторых фильтрационных течений //Радиоэлектроника и информатика. 2004. № 4. С. 5861. 20. Lamtyugova S.N., Sidorov M.V. Numerical analysis of the external slow flows of a viscous fluid using the Rfunction method. J. Eng. Math. 2015. Vol. 91. P. 59-79. DOI 10.1007/s10665-014-9746-X.

\section{Transliterated bibliography:}

1. Blishun A.P., Sidorov M.V. Metod chislennogo analiza stacionarnogo fil'tracionnogo techenija pod gidrotehnicheskim sooruzheniem v kusochno-odnorodnomu grunte. Visnik Zaporiz'kogo nacional'nogo universitetu. Serija: fiziko-matematichni nauki. 2012. № 2. P. 5-12.

2. Blishun A.P., Sidorov M.V., Jalovega I.G. Matematiche-skoe modelirovanie i chislennyj analiz fil'tracionnyh techenij pod gidrotehnicheskimi sooruzhenijami s pomoshh'ju. Radiojelektronika i informatika. 2010. № 2. P. 40-46.

3. Blishun A.P., Sidorov M.V., Jalovega I.G. Primenenie metoda R-funkcij $\mathrm{k}$ chislennomu analizu fil'tracionnyh techenij pod gidrotehnicheskimi sooruzhenijami. Visnik Zaporiz'kogo nacional'nogo universitetu. Serija: fizikomatematichni nauki. 2012. № 1. P. 50-56.

4. Bomba A.Ja., Bulavac'kij V.M., Skopec'kij V.V. Nelinijni matematichni modeli procesiv geogidrodi- namiki. K.: Nauk. dumka, 2007. 292 p.

5. Vabishhevich P.N. Metod fiktivnyh oblastej v matemati-cheskoj fizike. M.: Izd-vo MGU, 1991. 156 p.

6. Vengers'kij $P$. Pro zadachu sumisnogo ruhu poverhnevih i gruntovih potokiv na teritorii vodozboru. Visnik L'viv. un-tu. Ser. prikl. matem. ta inf. Vip. 22, 2014. P. 41-53

7. Gibkina N.V., Rogovoj N.S., Sidorov M.V., Stadnikova A.V. Chislennyj analiz zadachi peremeshivanija vjazkoj zhidkosti, vyzvannogo sistemoj tochechnyh vihrej // Visnik Zaporiz'kogo nacional'nogo universitetu. Serija: fiziko-matematichni nauki. 2013. № 2. P. 11-21.

8. Zhukovskij N.E. Teoreticheskoe issledovanie o dvizhenii pochvennyh vod (1889). Polnoe sobr. soch., t. 7. M.: 1937. P. 9-33.

9. Konnor Dzh., Brebbia K. Metod konechnyh jelementov v me-hanike zhidkosti. L.: Sudostroenie, 1979. 264 p.

10. Kravchenko V.F., Rvachev V.L. Algebra logiki, atomarnye funkcii i vejvlety $\mathrm{v}$ fizicheskih prilozhenijah. M.: Fizmatlit, 2006. 416 p.

11. Lavrent'ev M.A., Shabat B.V. Metody teorii funkcij kompleksnogo peremennogo. M.: Nauka, 1973. 736 p.

12. Ljashko I.I., Velikoivanenko I.M., Lavrik V.I., Mistec'kij G.E. Metod mazhorantnyh oblastej $\mathrm{v}$ teorii fil'tracii. K. : Nauk. dumka, 1974. 202 p.

13. Ljashko N.I., Velikoivanenko N.M. Chislennoanaliticheskoe reshenie kraevyh zadach teorii fil'tracii. K. : Nauk. dumka, 1973. 264 p.

14. Maksimenko-Shejko K.V. R-funkcii v matematicheskom modelirovanii geometricheskih ob'ektov i fizicheskih polej. Kharkiv, IPMash NAN Ukraïni, 2009. 306 p.

15. Pavlovskij N.N. Teorija dvizhenija gruntovyh vod pod. gidrotehnicheskimi sooruzhenijami i ejo osnovne prilozhe-nija. Petrograd, Izd-vo Nauchn.-meliorac. in-ta, 1922. $752 \mathrm{p}$.

16. Polubarinova-Kochina P.Ja. Teorija dvizhenija gruntovyh vod. M.: Nauka, 1977. 664 p.

17. Rvachev V.L. Ob analiticheskom opisanii nekotoryh geometricheskih ob’ektov. Dokl. AN SSSR. 1963. 153, № 4. P. 765-768.

18. Rvachev V.L. Teorija R-funkcij i nekotorye ejo prilozhenija. K.: Nauk. dumka, 1982. 552 p.

19. Sidorov M.V., Storozhenko A.V. Matematicheskoe kom-p'juternoe modelirovanie nekotoryh fil'tracionnyh techenij. Radiojelektronika i informatika. 2004. № 4. P. 58-61.

20. Lamtyugova S.N., Sidorov M.V. Numerical analysis of the external slow flows of a viscous fluid using the Rfunction method. J. Eng. Math. 2015. Vol. 91. P. 59-79. DOI 10.1007/s10665-014-9746-x.

Надійшла до редколегії 23.02.2018

Рецензент: д-р фіз.-мат. наук, проф. Литвин О.М. Подгорний Олексій Русланович, аспірант кафедри прикладної математики ХНУРЕ. Наукові інтереси: математичне моделювання, чисельні методи, метод Rфункцій. Адреса: Україна, 61166, Харків, пр. Науки, 14, тел. (057) 7021436. E-mail: oleksii.podhornyi@nure.ua.

Podhornyj Oleksii Ruslanovich, postgraduate student of the Applied Mathematics Department, Kharkov National University of Radioelectronics. Scientific interests: mathematical modeling, numerical analysis, R-function's theory and its applications. Address: 14 Nauki ave, Kharkiv, Ukraine, 61166, tel. (057) 7021436. E-mail: oleksii.podhornyi@nure.ua. 